\title{
Normal values of signal-averaged electrocardiographic parameters and QT dispersion in infants and children
}

\author{
Emmanuelle Vialle, Rim Albalkhi, Marc Zimmerman, Béat Friedli* \\ Hôpital cantonal universitaire, Unit of Pediatric Cardiology and *Cardiology Division, Geneve, Switzerland
}

\begin{abstract}
Ventricular late potentials, and dispersion of the QT interval, are markers for risk of ventricular arrhythmias. Normal values for these parameters are well established in adults, but may not apply for children. This study has investigated the age dependency of signal averaged electrocardiographic parameters and QT dispersion in 111 normal children aged from 5 days to 16 years. The results indicate that parameters change with age: duration of filtered QRS and low amplitude $(<40 \mu \mathrm{V})$ terminal signal increase with age, especially in the younger patients. Filtered $\mathrm{QRS}$ is $88.9 \pm 7.87 \mathrm{~ms}$ in infants, and increases to $108.7 \pm 8.51$ in teenagers $(p<0.001)$. Low amplitude terminal signals are $17.0 \pm 3.44 \mathrm{~ms}$ in infants, and $24.5 \pm 5.64 \mathrm{~ms}$ in teenagers $(p<0.001)$. Root mean square of the last $40 \mathrm{~ms}$ decreases with age, but remains stable after the age of 10 years $(122.4 \pm 33.30 \mu \mathrm{V}$ in infants, $60.9 \pm 31.27$ in teenagers, $p<0.001)$. QT dispersion, on the other hand, does not change significantly with age. The mean value for the whole group is $36 \pm 13.7 \mathrm{~ms}$. A weak but significant correlation exists between QT dispersion and filtered QRS. Thus, age must be taken into consideration when interpreting signal-averaged electrocardiograms, but not when measuring QT dispersion.
\end{abstract}

Keywords: QT dispersion; signal-averaged electrocardiogram; arrhythmias in the young

$\mathrm{V}$ ENTRICULAR LATE POTENTIALS, AS DETECTED by the high gain signal-averaged electrocardiogram, and dispersion of the Q-T interval, are both considered markers for risk of ventricular arrhythmias and sudden death, especially in adults with coronary arterial disease.$^{1-5}$ This has prompted similar investigations in children at risk for ventricular arrhythmias and sudden death, mostly patients who have undergone open heart surgery. Ventricular late potentials have, indeed, been observed in a certain percentage of such patients. ${ }^{6-8}$

Standards for analysis of the signal-averaged electrocardiogram and normal values in adults have been issued by an international task force. ${ }^{9}$ These criterions, however, may not apply to children. To the best of our knowledge, only 3 reports exist relating to signal-averaged electrocardiographic

Correspondence to: Béat Friedli, M.D., Hôpital cantonal universitaire, Unité de Cardiologie Pédiatrique, 1211 GENEVE 14, Switzerland. Tel: 41223824580 ; Fax: 41223824624 ; E-mail: beat.friedli@hcuge.ch

Accepted for publication 30 June 1999 parameters in normal children and infants. ${ }^{10-12}$ Furthermore, again to our knowledge, no data have been published regarding QT dispersion as seen in the electrocardiograms of normal infants and children. The aim of the present study, therefore, was to evaluate age dependency of signal-averaged electrocardiographic parameters and QT dispersion in infants and children from birth to the age of 16 years.

\section{Materials and methods}

A total of 111 children were studied ( 51 girls and 60 boys). Their ages ranged from 5 days to 16 years, with a mean of 6.5 years. All were seen by a pediatric cardiologist who ruled out any significant heart defect. In 79 cases, the diagnosis was functional murmur. In 9 cases, a small ventricular septal defect was found which closed spontaneously in all. In the remaining children, the reason for cardiac consultation was minimal patency of the arterial duct in 13 small infants, and chest pain in 10 . No child was on any medication. 
Signal-averaged electrocardiograms were recorded after informed consent was obtained from the children and/or their parents.

Signal-averaged electrocardiograms were recorded on a Marquette Mac 15 intrument. Silver chloride electrodes were placed to obtain the 3 Frank orthogonal leads, after careful preparation of the skin with a mixture of ether and alcohol. The input amplifier has a frequency response of $0.05-300 \mathrm{~Hz}$. Data are acquired at 1,000 samples per second and $1.2 \mu \mathrm{V} / \mathrm{bit}$, and transmitted to the cart. The "HI-RES" software delineates QRS complexes and correlates them with a template in frequency domain to compute an average complex ( $40 \mathrm{~Hz}$ FFT filter with a $6 \mathrm{~dB}$ /octave roll-off). 150 to 300 beats were averaged with the aim to reduce baseline noise to less than $0.5 \mu \mathrm{V}$. In this study, the high-pass filter was set at $40 \mathrm{~Hz}$ and the low-pass filter at $250 \mathrm{~Hz}$. A vector magnitude is calculated as $v=\sqrt{x^{2}}+y^{2}+z^{2}$. The noise level is measured as an average in a $30-\mathrm{ms}$ window in the ST segment. The end of the QRS complex is automatically determined at twice the baseline noise. The following parameters were measured: the filtered QRS duration, in milliseconds, the duration of low amplitude terminal signals, again in milliseconds, defined as the interval between the end of total QRS and the point determined retrogradely where the QRS voltage exceeds $40 \mu \mathrm{V}$; and the root mean square voltage of the terminal 40 milliseconds of the filtered QRS complex, in $\mu V^{13,14}$

The QT interval was measured by hand on standard 12 lead electrocardiograms at a paper spead of $25 \mathrm{~mm} / \mathrm{s}$. The measurement was from the beginning of the QRS complex until the $T$ wave returned to the isoelectric line. $U$ waves were rarely observed. If present, the nadir of the $\mathrm{T}$ wave was identified as the termination of the QT interval. The rate corrected QT interval was calculated according to BAZETT's formula :

$$
\mathrm{QTC}=\frac{Q T}{\sqrt{\mathrm{RR}}}
$$

using for the correction the RR interval preceding the measured complex.
Although this formula has its limitations, especially when the heart rate is fast, ${ }^{15}$ it is still the most commonly used means of correcting the QT interval for heart rate.

QT dispersion was calculated as the longest minus the shortest QT interval, the intervals being measured in all leads on the 12 lead electrocardiogram, except those with an isoelectric QT interval.

All measurements were made by two independant observers and the average of both measurements was taken. Mean interobserver difference was $5.7 \mathrm{~ms}$.

\section{Age groups}

The 111 patients were divided into 4 age groups: 25 newborns and infants aged from 0 to 12 months; 36 preschool children from 1 to 5 years; 27 school children from 6 to 10 years; and 23 teenagers aged from 11 to 16 years.

\section{Statistics}

Mean and standard deviation where calculated for all parameters for each age group. The mean values of each parameter were then compared by a one way analysis of variance. If a significant difference between groups was present, multiple comparison tests were performed using the StudentNewmann-Keuls test.

Correlation between QT dispersion and the 3 signal-averaged electrocardiographic parameters were sought by linear regression analysis.

\section{Results}

Table 1 shows the results of all parameters for the different age groups. Correlation between QT dispersion and signal-averaged electrocardiographic parameters: There was a weak but significant correlation $(\mathrm{r}=0.26, p<0.01)$ between QT dispersion and filtered QRS. Correlation coefficients with low amplitude terminal signals $(r=0.03)$ and root mean square of last $40 \mathrm{~ms}(\mathrm{r}=-0.14)$ were very weak and insignificant.

Table 1

\begin{tabular}{ccccccc}
\hline Age group & N & QRSf $(\mathrm{ms})$ & LAS $40(\mathrm{mcV})$ & RMS 40 (mcV) & dQT (ms) & dQTc(ms) \\
\hline $0-12$ mo & 25 & $88.9 \pm 7.87$ & $17.0 \pm 3.44$ & $122.4 \pm 33.30$ & $31 \pm 12.7$ & $48 \pm 15.1$ \\
$1-5$ yrs & 36 & $97.8 \pm 8.11$ & $20.6 \pm 7.36$ & $89.0 \pm 40.76$ & $37 \pm 11.1$ & $53 \pm 15.6$ \\
$6-10$ yrs & 27 & $105.1 \pm 5.84$ & $24.2 \pm 5.97$ & $61.3 \pm 28.78$ & $39 \pm 15.4$ & $46 \pm 15.2$ \\
$11-16$ yrs & 23 & $108.7 \pm 8.51$ & $24.5 \pm 5.64$ & $60.9 \pm 31.27$ & $39 \pm 15.2$ & $52 \pm 14.0$ \\
\hline
\end{tabular}

Table 1. Mean and standard deviation for SAECG paramerers and QT dispersion (dQT) in the different age groups. dQTc refers to dispersion of rate corrected QT intervals (see text). 
Signal-averaged electrocardiogram

Baseline noise for these recordings was $0.47 \pm$ $0.17 \mu \mathrm{V}$. Filtered QRS was age related, the value progressing with age (Fig.1). Differences between age groups were highly significant between the first 3 groups $(p<0.01)$. Progression continued in the teenagers but did not reach statistical significance compared to the other groups.

Low amplitude terminal signal duration was very low for infants, and progressed significantly up to the age of 10 years $(p<0.05)$. After this age, no significant differences in low amplitude signals was observed compared with the younger patients (Fig.2).

Root mean square of last $40 \mathrm{~ms}$ decreased with age, the changes being highly significant for the groups younger than teenage $(p<0.01)$. This parameter did not exhibit a significant difference between the older age groups (Fig.3).

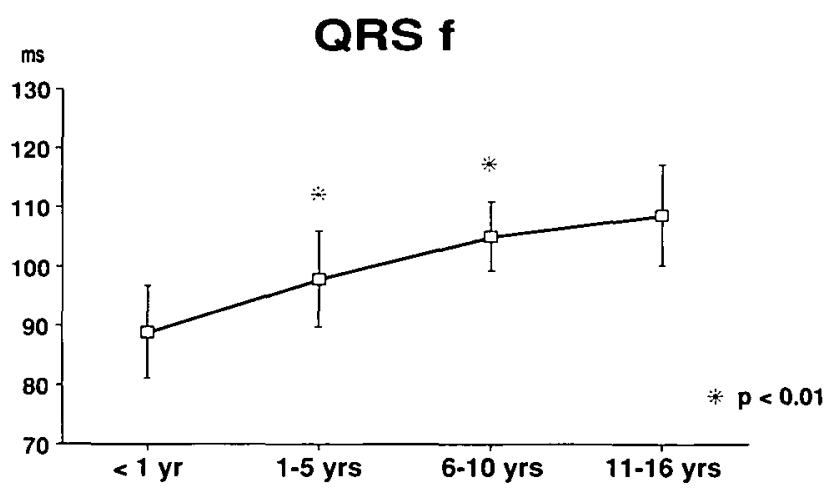

Figure 1.

Progression of the filtered $Q R S(Q R S f)$ duration with age. Asterisks indicate significant differences compared to previous age group. Bars are one standard deviation.

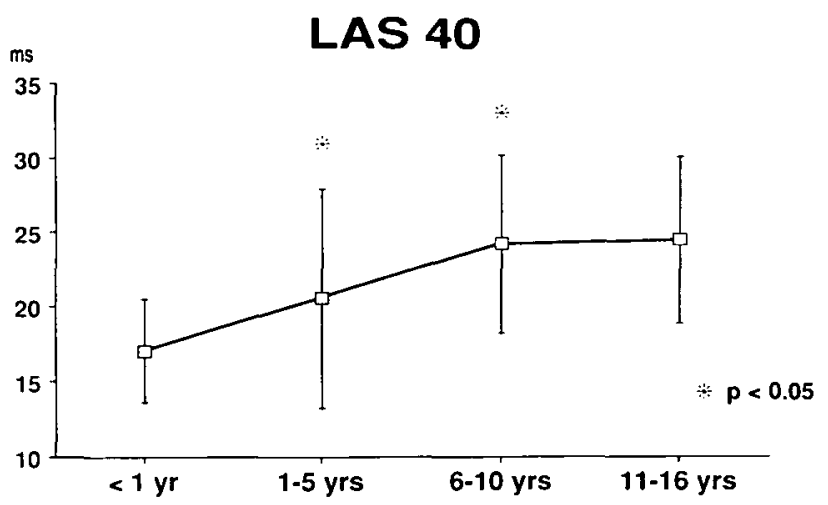

Figure 2.

Progression of duration of low amplitude signals $(<40 \mu \mathrm{V})$ in the terminal QRS (LAS 40), with age. Asterisks indicate significant differences compared to previous age group.
Correlation coefficients between signal-averaged electrocardiographic parameters and respectively age, body height and body surface area are shown in Table 2.

Although height showed a marginally better correlation, we have chosen for practical reasons to make age rather than height the criterion for groups. This is because, in current practice, all documents routinely mention the age of a patient, but not necessarily their height.

QT dispersion showed a tendency to increase between infants and preschool children, but this did not reach statistical significance. No change was noted in the older patients (Fig.4).

Corrected QT dispersion was found to have surprisingly high values, compared to the uncorrected values, and showed no changes with age. The reason for the high value was found to be sinus arrhythmia, which is common in children. Indeed, whereas changes in RR intervals are sizable in sinus

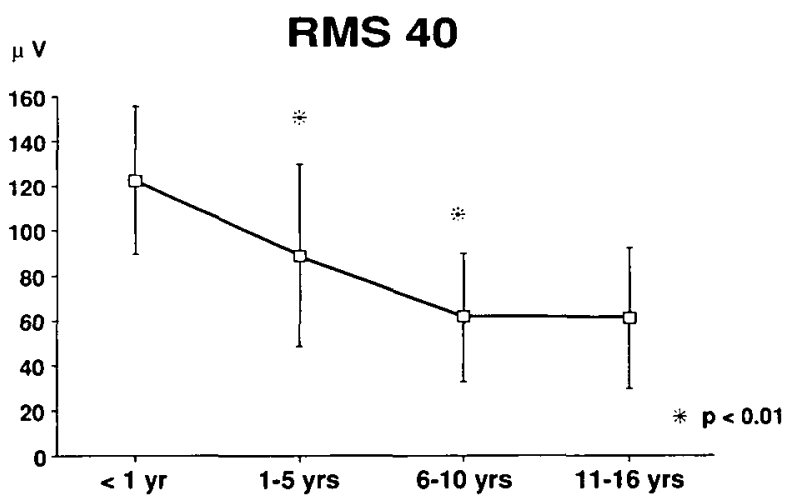

Figure 3.

Changes with age of the root mean square of the last $40 \mathrm{~ms}$ (RMS 40). Asterisks indicate significant change compared to previous àge group.

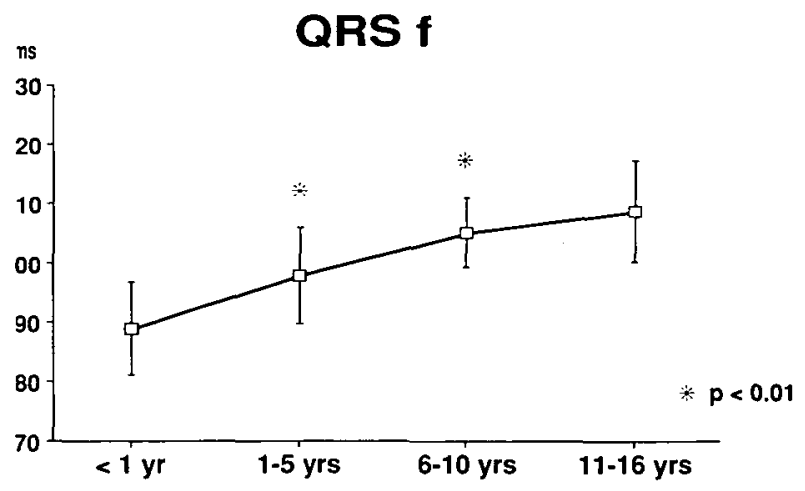

Figure 4.

Mean and standard deviation of $Q T$ dispersion $(d Q T)$ in the 4 age groups. There are no significant differences, although there is a trend towards lower $Q T$ dispersion in the infant group. 
Table 2. Correlation between SAECG parameters and age, body height, body surface area (BSA)

\begin{tabular}{llll}
\hline & Age & BSA & Body height \\
\hline QRSf & $r=0.64$ & $r=0.62$ & $r=0.67$ \\
LAS 40 & $r=0.32$ & $r=0.31$ & $r=0.36$ \\
RMS 40 & $r=0.50$ & $r=0.48$ & $r=0.55$ \\
\hline
\end{tabular}

arrhythmia, absolute QT intervals showed no changes. Correcting the $\mathrm{QT}$ intervals with the BAZETT's formula using the preceding $R R$ interval thus leads to spurious variations in corrected QT and an overestimation of dispersion (Fig.5, see Discussion).

\section{Discussion}

Ventricular late potentials, and abnormal QT dispersion, are well established markers indicating a risk of ventricular arrhythmias and sudden death in adults with coronary arterial disease and cardiomyopathy. ${ }^{1-5}$ This has prompted similar investigations in children at risk for ventricular arrhythmias, particularly those who have undergone open heart surgery, ${ }^{6-8}$ with the emphasis on the significance of ventricular late potentials. More recently, QT dispersion has also been studied in children after repair of tetralogy of Fallot. ${ }^{16,17}$

Normal values for all these parameters in adults have been compiled by an international task force, ${ }^{9}$ but they may not apply to children. There are now a few reports on normal values for the signalaveraged electrocardiogram in children, ${ }^{10,11,12,18,19}$ only 3 including infants. To our knowledge, the potential age dependency of QT dispersion has not been studied.

It is important, therefore, that our study has shown clear changes in the 3 most often used time domain criterions for the signal averaged electrocardiogram. Thus, filtered QRS increases with age, as has been previously demonstrated, and low amplitude terminal signals also increase with age. In our study, these changes were significant for the 3 youngest age groups. In teenagers, filtered QRS showed further prolongation, but this did not reach statistical significance. Low amplitude terminal signals, in contrast, do not change between the "school-age" and the "teenage" group.

The root mean square of last $40 \mathrm{~ms}$ has high values in infants which decrease progressively in the later age groups. As with low amplitude terminal signals, no further changes occured between those immediately above and below the age of 10 . In infants with a short QRS complex, the last $40 \mathrm{~ms}$

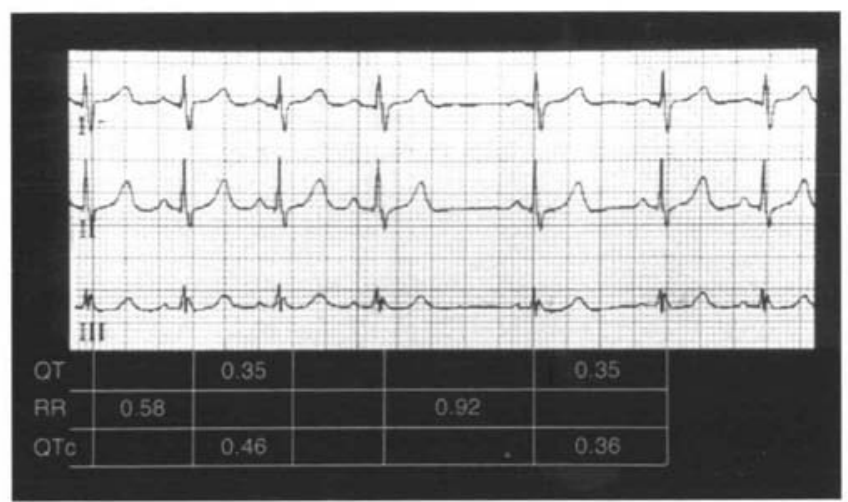

Figure 5 .

Electrocardiogram of a child with sinus arrbytbmia. QT interval bas been measured for a short and for a long cycle. QT does not change after the long cycle. Therefore the calculation of corrected $Q T$ introduces a spurious "dispersion" (see text).

may reach into the high amplitude area of the main body of the QRS." Because of this, it has been advocated to use only the last $30 \mathrm{~ms}$ of the determination of root mean square of last $40 \mathrm{~ms}$. For the purpose of comparison with older children and with adults, we have chosen to keep the generally used last $40 \mathrm{~ms}$ of the complex

Previous studies regarding normative data in children have shown age dependent changes, similar to our population. ${ }^{11,12,18,19}$ Minor differences in absolute values may be due either to a different averaging system used or to racial differences.

QT dispersion looks at repolarization abnormalities, and is used increasingly to predict risk of ventricular arrhythmias. This parameter has been used in combination with abnormalities of depolarization (late potentials) to detect patients at risk. ${ }^{4} \mathrm{It}$ is not known whether QT dispersion is age dependent in children. Our data indicate that there is no significant change from birth to the age of 16 , although there is a tendency for the QT dispersion to increase with age, especially between infants and preschool children.

The mean and standard deviations of QT dispersion for all the ages we studied are similar to those published for adults ${ }^{20}$ and children, ${ }^{21}$ with a mean value between 30 and $40 \mathrm{~ms}$. The upper 95 th percentile is 0.63 . Values above this, therefore can be considered abnormal.

QT dispersion or corrected QT dispersion? It is obvious from our Table that the corrected value for QT dispersion has surprisingly high values, values which are higher than QT dispersion in all age groups. The reason for this is seen in Fig. 5. Children often have marked sinus arrhythmias. The RR interval, which enters the Bazett 
formula, can therefore vary widely from beat to beat. The QT interval, in contrast, hardly changes during sinus arrhythmia. In consequence, correction for the preceding $R R$ interval introduces a spurious dispersion of the QT interval. Some years ago, Garson et al. ${ }^{22,23}$ studied the QT interval and its variations during sinus arrhythmia, comparing a group of patients suffering from long QT syndrome with a control group of normals. They observed a significant variation of QT duration during sinus arrhythmia in long QT patients, but not in normal controls. It has also been shown in a recent pacing study ${ }^{24}$ that sudden change of heart rate does not change the QT interval immediately, but only after a delay. Because of this, we believe that corrected QT should not be used to calculate dispersion, especially in children in whom sinus arrhythmia is common. Even in adults, the need for rate correction when calculating QT dispersion has been questioned. ${ }^{25}$

We wondered whether there would be a correlation between one of the parameters looking at depolarization, namely the signal-averaged electrocardiogram, and QT dispersion, which is a variable of repolarization. In our normal population, a weak correlation was found only between QT dispersion and filtered QRS, with no correlation observed with the other parameters of the signal-averaged electrocardiogram.

\section{Limitations of the study}

Normal values for the signal-averaged electrocardiogram in infants and children defined in the present study may not be applicable to different signal-averaging systems because they may vary with the type of band-pass filters used, the type of lead system, the number of averaged beats or the definition of baseline noise. ${ }^{9,13}$ Also, other filter settings may give somewhat different results. We purposely have chosen the high pass filter at 40 $\mathrm{Hz}$, this being the most commonly recommended setting.

Despite the limitations, we conclude that signalaveraged electrocardiographic parameters are age dependent in infants and children. Filtered QRS increases with age, low amplitude terminal signals increase, and root mean square of last $40 \mathrm{~ms}$ decreases. These changes are most marked in the very young, and become minimal after age 10 years. QT dispersion on the other hand, although somewhat lower in the infants, does not show statistically significant changes with age. The mean and upper limits of this parameter is similar to the values found in the adults.

\section{Acknowledgements}

We would like to thank Dr. Rimensberger for his help with the statistical analysis, and Mrs Dufaud for preparing the manuscript. This study was supported by the Swiss Cardiac Foundation and the "Fonds Gerbex-Bourget".

\section{References}

1 Breithardt G, Borggrefe M. Pathophysiological mechanisms and clinical significance of ventricular late potentials. Eur Heart J 1986;7:364-385

2 Simpson MB. Use of signals in the terminal QRS complex to identify patients with ventricular tachycardia after myocardial infarction. Circulation 1981;64:235-242.

3 Yunus A, Gillis AM, Duff HJ, Wyse DG, Mitchell LB. Increased precordial QTc dispersion predicts ventricular fibrillation during acute myocardial infarction. Am J Cardiol 1996;78:706.

4 Goldner B, Brandspiegel HZ, Horwitz L, Jadonath R, Cohen TJ. Utility of $Q T$ dispersion combined with the signal-averaged electrocardiogram in detecting patients susceptible to ventricular tachyarrhythmia. Am J Cardiol 1995;76:1192-1193.

5 DJ Pinsky, RR Sciacca, JS Steinberg. QT dispersion as a marker of risk in patients awaiting heart transplantation. J Am Coll Cardiol 1997;29:1976-1584

6 Zimmermann M, Friedli B, Adamec R, Oberhänsli I Frequency of ventricular late potentials and fractionated right ventricular electrograms after operative repair of tetralogy of Fallot. Am J Cardiol 1987;59:448-453

7 Zimmermann $M$, Friedli $B$, Adamec R, Oberhänsli I. Ventricular late potentials and induced ventricular arrhythmias after surgical repair of tetralogy of Fallot. Am J Cardiol $1991 ; 67: 873-878$.

8 Janousek J, Paul T, Bartakova H. Role of late potentials in identifying patients at risk for ventricular tachycardia after surgical correction of congenital heart disease. Am J Cardio 1995; 75:146-150.

9 Breithardt G, Cain ME, El-Sherif N, Flowers N, Hombach V Janse $M$, Simson MB, Steinbeck G. Standards for analysis of ventricular late potentials using high resolution or signal averaged electrocardiography. Eur Heart J 1991;12:473-480.

10 Hayabuchi Y, Matsuoka S, Kubo M, Akita H, Kuroda Y. Agerelated criteria for signal-averaged electrocardiographic late potentials in children. Ped Cardiol 1994;15:107-111.

11 Fallah-Najmabadi H, Dahdah NS, Palcko M, Mehta SK Normal values and methodologic recommendations for signalaveraged electrocardiography in children and adolescents. Am J Cardiol 1996;77:408-412.

12 Jimbo $\mathrm{O}$, Zhang J. Seki T, Ogawa S. Criteria for evaluating abnormal signal-averaged electrocardiogram in children classified by age, body surface area and height. Jpn Circ J 1996;60:228-238

13 Zimmermann M, Adamec R, Simonin P, Fromer M, Richez J. Noninvasive detection of ventricular late potentials: direct comparison of 7 different high-gain recording systems. Am J Noninvas Cardiol 1992;6:154-167.

14 Shankara Reddy BR, Christenson DW, Rowlandson GI. Highresolution ECG on a standard ECG cart. J Electrocardiol 1988;21(supp):S74-S79.

15 Sagie A, Larson MG, Goldberg RJ Bengtson JR, Levy D. An improved method for adjusting the QT interval for heart rate (the Framingham heart study). Am J Cardiol 1992;70:797-801.

16 Daliento L, Caneve F, Turrini P, Buja G, Nava A, Milanesi O Stellin $G$, Rizzoli $G$. Clinical significance of high-frequency, 
low-amplitude electrocardiographic signals and QT dispersion in patients operated on for tetralogy of Fallot. J Am Coll Cardiol 1995;76:408-411.

17 Gatzoulis MA, Till JA, Redington AN. Depolarization-repolarization inhomogenecity after repair of tetralogy of Fallot. Circulation 1997; 95, 401-404.

18 Vaksmann G, Elkonen M, Duhamel A, Godart F. Signalaveraged electrocardiography in healthy children : influence of age, body size and gender. PACE 1996;19:1629-1634.

19 Davis AM, McCrindle BW, Hamilton RM, Moore-Coleman P, Gow RM. Normal values for the childhood signal-averaged ECG. PACE 1996;19:793-801.

20 Hill JA, Friedman PL. Measurement of QT interval and QT dispersion. Lancet 1997;349:894-895.
21 Shah MJ, Wiesand TS, Rhodes LA, Berul CI, Vetter VL. QT and JT dispersion in children with long QT syndrome. J Cardiovasc Electroph 1997;8:642-648.

22 Garson A. How to measure the QT interval - what is normal ? Am J Cardiol 1993;72:14B-16B.

23 Martin AB, Perry JC, Robinson JL, Zareba W, Moss AJ, Garson A Jr. Calculation of QTc duration and variability in the presence of sinus arrhythmia. Am J Cardiol 1995;75:950-952.

24 T.S. Faber, A. Jeron, A. Würth, Just H, Zehender M. Do we need correction for heart rate when assessing QT dispersion for risk stratification? Eur Heart J 1997;18, Abstract Supplement: 199.

25 Malik M, Camm AJ. Mystery of QTc interval dispersion. Am J Cardiol 1997;79:785-78 